Original Article

\title{
Age-related differences in brain activity during physical and imagined sit-to-stand in healthy young and older adults
}

Srisupornkornkool Kanokwan, PhD, PT ${ }^{1)^{*}}$, Wongcheen Pramkamol, BS, $\mathrm{PT}^{1}$, Klongkhayan Wipatcharee, BS, PT ${ }^{1}$, Warnjing Warissara, BS, PT ${ }^{1)}$, Rassameejan Siwarit, MD $^{2)}$, Somthavil Sompiya, MS, $\mathrm{PT}^{3)}$, Boonyarom Onuma, PhD, $\mathrm{PT}^{3)}$, Suvobrata Mitra, $\mathrm{PhD}^{4)}$

1) Department of Physical Therapy, Faculty of Allied Health Sciences, Naresuan University: Phitsanulok 65000, Thailand

2) Buddhachinaraj Hospital, Thailand

3) Department of Rehabilitation and Movement Sciences, Faculty of Sports Science, Kasetsart University, Thailand

4) Division of Psychology, Nottingham Trent University, United Kingdom

\begin{abstract}
Purpose] The purpose of this study was to investigate whether healthy young and older people differ in self-reported movement time and brain activity pattern as indicated by electroencephalography during physical and imagined sit-to-stand movements. [Participants and Methods] Twenty healthy young (aged 20-29 years) and 19 older (aged 60-69) participants performed physical and imagined sit-to-stand movements while their self-reported movement times and electroencephalography were recorded. [Results] No age-related differences were found in self-reported movement time for physical or imagined sit-to-stand. In the frontal and temporal regions, electroencephalography showed a beta wave $(14-17 \mathrm{~Hz})$ for all conditions in both young and older adults. In the parietal and occipital regions, during physical sit-to-stand trials, both groups showed a beta wave in both regions. During imagined sit-to-stand trials, however, young participants showed a high alpha wave $(10.6-13 \mathrm{~Hz})$ in the parietal and a low alpha wave $(8-10.5 \mathrm{~Hz})$ in the occipital region, whereas older participants showed all three (alpha and beta) waves in the parietal and occipital regions. [Conclusion] Although no age-related differences were found in the ability to generate motor imagery, brain activity pattern as indicated by electroencephalography was dissimilar between young and older participants during motor imagery.

Key words: Electroencephalography, Motor imagery, Sit-to-stand
\end{abstract}

(This article was submitted Dec. 14, 2018, and was accepted Feb. 19, 2019)

\section{INTRODUCTION}

Sit-to-stand (STS) is considered a basic movement of our daily lives as many activities are performed in the standing position. In addition, STS from both sitting and lying positions is often essential for moving from one place to another, ${ }^{1,2)}$ Generally, people perform STS approximately 45-65 times a day. STS formation relies heavily on muscle strength, particularly of the leg muscles, and balance ${ }^{3-5}$. Previous studies have found that the momentum used for STS can be up to 4.7 times the person's body weight. Consequently, performing STS is one of the more challenging activities for any elderly person who is in poor health or has issues with balance ${ }^{5)}$. Deterioration in STS ability in older people is associated with higher risk of disability $^{6}$, falling ${ }^{7)}$, hospitalization ${ }^{8)}$, and nursing home admission ${ }^{9)}$.

*Corresponding author. Srisupornkornkool Kanokwan (E-mail: kanokwans@nu.ac.th)

(C2019 The Society of Physical Therapy Science. Published by IPEC Inc.

(c) (1) $\odot$ This is an open-access article distributed under the terms of the Creative Commons Attribution Non-Commercial No Derivatives

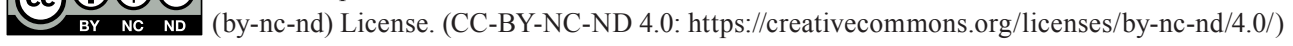


Enhancing STS, then, becomes a primary objective for revival programs that aid patients who are elderly and have mobility issues by helping them stand safely and more easily ${ }^{10)}$. STS revival or enhancement programs were developed to help people build the muscle strength required to perform STS effectively. The programs are generally comprised of exercises that use resistance to build muscle strength ${ }^{11,12)}$ and task-specific training ${ }^{10,13)}$. In task-specific training, the repetition of STS helps strengthen the leg muscles, which leads to better STS performance results. However, performing exercises that require body movement may pose a limiting challenge to patients who are physically weak, unbalanced, or have impaired movement. Hence, what needs to be developed is a way to stimulate the central nervous system (CNS) to improve motor planning. The covert activity termed motor imagery (MI) involves planning and mentally simulating movements without physically executing them ${ }^{14}$. Although MI does not involve overt motion, the processes that occur during MI are similar in several ways to those that occur during physical movement ${ }^{11,15)}$. Both show the speed-accuracy tradeoff described in Fitts' Law, and appear to use similar patterning of movement ${ }^{16)}$. Likewise, neurophysiological evidence supports a unitary mechanism for action representation and execution ${ }^{17}{ }^{18}$, and brain imaging suggests common loci of cortical activation between motor imagery and execution ${ }^{19-21)}$. In view of these similarities, MI has been considered a form of movement simulation ${ }^{14)}$.

As MI appears to activate the motor planning and execution pathways, there has been significant interest in investigating

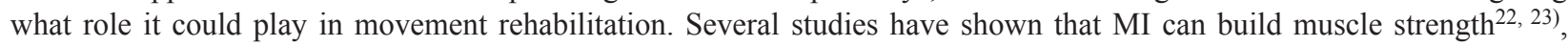
arm movement speed ${ }^{24)}$, hip joint movement ${ }^{25)}$, and balance-control ability ${ }^{26,27)}$. However, to our knowledge, only a few studies have investigated the potential of $\mathrm{MI}$ in the context of STS ${ }^{28)}$. According to previous literature reviews, research on the impact of MI on higher-level control for complex body movements, especially STS, is still rare due to the fact that most research focuses on mental chronometry which is characteristic of higher-level control. Previous results showed there was no difference in the duration of actual body movement and MI.

According to Skoura et al. ${ }^{28)}$ 's study on MI, results for mental chronometry between actual and imagined stand-sit-stand movements revealed that imagined stand-sit-stand displays a faster outcome and takes less time than physical stand-sit-stand. Regarding the comparison between the time needed for the acts of standing up and sitting down, it was shown that physical standing up takes less time than sitting down. However, during imagined STS, no difference was found between the time taken to stand up and the time taken to sit down. Consequently, movement duration was underestimated while imagining the whole movement. Moreover, this finding suggested that normal aging does not affect the ability to internally simulate motor actions. Another study on $\mathrm{MI}^{29)}$, compared physical and imagined standing up in healthy young and older participants, and found that the time for physical STS was similar to that of imagined STS ${ }^{29}$. This study also demonstrated that the ability to generate MI did not differ between young and older participants. However, further studies are needed to clarify the ability of MI to be a way of accessing the higher-level of control of STS movements.

From these results, it should be noted that the time needed to physically move certain body parts, such as arms, or even the whole body as in walking or STS, is similar to the time needed to imagine such movements. However, there is still no detailed understanding of the ways in which physical movement and MI are similar or different across the age range, and for any type of movement, especially complex movement. Task-level action planning and effector-level movement control are often considered modular elements of goal-directed action $^{30,31)}$, and it has been suggested that the connection between these processes deteriorates with age. What's more, previous research has mostly emphasized measurement outcome at the behavioral level only (e.g. movement time), which gives little information about the neural processes involved in the higherlevel control of body movement. One way to non-invasively investigate differences in the higher-level control system at work during MI is to track neurophysiological measures such as Electroencephalography (EEG) characteristics. There is currently a lack of research on EEG patterns during MI of full-body movements such as STS.

The present study monitored EEG characteristic during physical and imagined sit-to-stand. The EEG is a test that records the electrical signals of the brain using small, metal discs (electrodes) attached to scalp. The EEG is typically described in terms of rhythmic activity. The rhythmic activity is major divided into 4 bands by frequency, including beta $(>14 \mathrm{~Hz})$, alpha $(8-14 \mathrm{~Hz})$, theta $(4-7 \mathrm{~Hz})$ and delta $(<4 \mathrm{~Hz})$. As MI appears to activate the motor planning, this research expected that rhythmic activity in different brain areas may be similar during physical and imagined STS. Therefore, the objective of this study was to investigate brain activity during physical and imagined sit-to-stand. Also, the study clarified the ability of MI to be a way of accessing the higher-level of control of STS movements in age-related difference.

\section{PARTICIPANTS AND METHODS}

This research study used an experimental design. This study was designed to monitor self-reported movement time and EEG during physical and imagined STS. Twenty healthy young adults (20-29 yrs) and 19 healthy older adults (60-69 yrs) ${ }^{32)}$ took part in the study, receiving payment for their participation. Participants were recruited from the local university's student and staff population as well as from people living around the university. All participants were screened to ensure they had an unimpaired ability to be able to stand up from a sitting position multiple times per session. The screening also ensured they had no significant medical history, no current problems affecting balance or everyday motor function, and no mental disorders. Participants with a Mini-Mental State Examination (MMSE) score below 22 or a Movement Imagery Questionnaire-Revised (MIQ-R) score below 20 were excluded.

Potential participants were given advanced information regarding general task requirements and the opportunity to seek 
Table 1. Participant demographics

\begin{tabular}{lrr}
\hline \multicolumn{1}{c}{ Participant demographics } & $\begin{array}{c}\text { Young adults } \\
\text { Mean } \pm \text { SD }\end{array}$ & \multicolumn{1}{c}{$\begin{array}{c}\text { Older adults } \\
\text { Mean } \pm \text { SD }\end{array}$} \\
\hline Age (yrs) & $24.05 \pm 3.05$ & $65.00 \pm 2.36$ \\
MMSE score & $28.65 \pm 1.46$ & $26.05 \pm 2.65$ \\
MIQ-R score: Kinesthetic imagery (KI) & $23.2 \pm 2.76$ & $26.26 \pm 1.24$ \\
MIQ-R score: Visual imagery (VI) & $24.3 \pm 2.87$ & $26.16 \pm 1.30$ \\
Vividness & $1.2 \pm 0.41$ & $1.16 \pm 0.37$ \\
\hline
\end{tabular}

clarification before choosing to participate. All participants provided written informed consent before taking part in the study. The study received ethical approval from the Ethics Committee (HSSREC) of Naresuan University and Buddhachinaraj Phitsanulok Hospital.

The experiment was conducted in a quiet room within a diagnostic suite at Buddhachinaraj Phitsanulok Hospital. Participants were instructed to come dressed in comfortable clothing. They were asked to take their seat on a vertically adjustable chair set to the height of their lower legs. Participants' feet rested on the floor with their heels approximately $10 \mathrm{~cm}$ apart. Participants' ankles were positioned with $\sim 10^{\circ}$ of dorsiflexion and knees with $\sim 100-105^{\circ}$ of flexion ${ }^{33)}$ using a handheld goniometer. The position of the feet on the floor was then marked with tape. Participants' thighs were positioned with the edge of the chair at two-thirds of their thigh length. This position was marked by putting tape on their thighs and on the seat behind their buttocks. Participants were asked to keep their arms by their sides. Before each trial, the position of the torso, legs, and feet were checked and corrected as necessary. Next, electrodes were attached to participants' scalp to monitor EEG at the frontal, parietal, temporal and occipital lobes before and during physical and imagined STS. EEG (Nihon Kohden EEG 4418A) recording was performed using 21 active electrodes and two reference electrodes (mastoids). Impedance for all electrodes was kept below $100 \mathrm{M} \Omega$. Signal was sampled at $1,000 \mathrm{~Hz}$ with 16 bit ADC resolution and filtered in $0.08-300 \mathrm{~Hz}$. Participants had to finish their meals per usual to prevent hypoglycemia during the EEG test. Furthermore, participants were not allowed to consume any kind of caffeine, including coffee, tea, soft drinks or chocolate, at least 8-12 hours before the EEG test. The higher-level control system is stimulated by caffeine, thus the consumption of caffeine would directly impact EEG results.

Each participant first performed the physical STS movement (three recorded trials), followed by the imagined STS movement (three recorded trials), with 5 minutes of rest in between or however long was needed before they had no sign of fatigue. Each set of three recorded trials was preceded by two practice trials. EEG was recorded throughout the period of performing physical and imagined STS. In conditions involving imagined movement, participants were asked to provide a vividness judgment after the practice trials and then again after the experimental trials to record their subjective impression of the strength of their imagined STS. To do so, participants indicated on a five-point scale how vividly they felt they had been able to imagine the movement (1=perfectly clear and as vivid as the feel of actual movement, $2=$ clear and reasonably vivid, $3=$ somewhat clear and vivid, $4=$ vague and dim and $5=$ no image at all).

At the beginning of each trial, participants were instructed to sit comfortably with their backs straight and hold a stop timer in their right hand (to provide self-report of movement completion), and then follow trial-specific instructions. In each trial, the participant awaited a pre-recorded, auditory, "Ready ... Go!" signal played by the movement-time software, and then performed a physical or imagined STS movement with their natural speed. In condition MI, participants were asked to relax prior to imagine the movement and then asked to focus on their own body-internal aspects of motor coordination (kinesthetic imagery with first-person perspective). Then, they were asked to press the left button of the handheld stop timer when they felt they had completed the STS movement and were "standing comfortably and steadily" (or imagining doing so). They were also asked to stay standing steadily until they heard the experimenter say, "Done." Participants were then asked to sit down, relax, and prepare for the next trial.

Self-reported movement time (self-reported MT) in physical and imagined was presented as mean and standard error of mean. Self-reported MT was analyzed using Wilcoxon Signed Rank Test when compared within group, and using MannWhitney Test when compared between groups. The significance value was set to $\mathrm{p}<0.05$.

For EEG pattern analysis, EEG features were extracted from the band corresponding to beta, alpha, theta and delta waves. These features represent the frequency distribution and the amount of changes in the frequency distribution. EEGs were presented as the number of participants and percentage. EEGs were analyzed using the Fisher's Exact Test. The significance value was set to $\mathrm{p}<0.05$.

\section{RESULTS}

The 20 healthy, young adults (20-29 yrs, $M_{\text {age }} 24.05 \pm 3.05$ yrs) and 19 healthy, older adults (60-69 yrs, $M_{\text {age }} 65.00 \pm$ $2.36 \mathrm{yrs}$ ) used in this study had no impaired ability to stand up from a sitting position and had no significant medical history nor current problems affecting balance or everyday motor function. Participants had MMSE scores over 22, MIQ-R scores over 20 and vividness around 1-2 (Table 1).

There was no significant difference in self-reported MT between physical and imagined STS in both young and older 
Table 2. Self-reported movement time (sec)

\begin{tabular}{lccc}
\hline & Young adults & Older adults & \multirow{2}{*}{ Mean \pm SEM } \\
Mean \pm SEM & $1.586 \pm 0.095$ & $2.166 \pm 0.147$ & $0.001^{*}$ \\
\hline Physical STS & $2.123 \pm 0.341$ & $2.279 \pm 0.382$ & 0.967 \\
Imagined STS & 0.198 & 0.469 & \\
$\mathrm{p}$ & & & \\
\hline
\end{tabular}

*Significant difference when comparing self-reported MT during physical and imagined STS between young and older adults.

Table 3. Electroencephalography (EEG) features during physical and imagined sit-to-stand (STS) in young adults

\begin{tabular}{|c|c|c|c|}
\hline Brain area & $\begin{array}{c}\text { Physical STS } \\
\text { number of participants (\%) }\end{array}$ & $\begin{array}{c}\text { Imagined STS } \\
\text { number of participants }(\%)\end{array}$ & $\mathrm{p}$ \\
\hline \multicolumn{4}{|l|}{ Frontal lobe } \\
\hline $14-17 \mathrm{~Hz}$ & $20(100)$ & $20(100)$ & \\
\hline $10.6-13 \mathrm{~Hz}$ & $0(0)$ & $0(0)$ & - \\
\hline $8-10.5 \mathrm{~Hz}$ & $0(0)$ & $0(0)$ & \\
\hline \multicolumn{4}{|l|}{ Temporal lobe } \\
\hline $14-17 \mathrm{~Hz}$ & $20(100)$ & $20(100)$ & \\
\hline $10.6-13 \mathrm{~Hz}$ & $0(0)$ & $0(0)$ & - \\
\hline $8-10.5 \mathrm{~Hz}$ & $0(0)$ & $0(0)$ & \\
\hline \multicolumn{4}{|l|}{ Parietal lobe } \\
\hline $14-17 \mathrm{~Hz}$ & $20(100)$ & $1(5)$ & \\
\hline $10.6-13 \mathrm{~Hz}$ & $0(0)$ & $19(95)$ & $<0.001^{*}$ \\
\hline $8-10.5 \mathrm{~Hz}$ & $0(0)$ & $0(0)$ & \\
\hline \multicolumn{4}{|l|}{ Occipital lobe } \\
\hline $14-17 \mathrm{~Hz}$ & $20(100)$ & $1(5)$ & \\
\hline $10.6-13 \mathrm{~Hz}$ & $0(0)$ & $0(0)$ & $<0.001^{*}$ \\
\hline $8-10.5 \mathrm{~Hz}$ & $0(0)$ & $19(95)$ & \\
\hline
\end{tabular}

*Significant difference when comparing EEG features between physical and imagined STS.

Table 4. Electroencephalography (EEG) features during physical and imagined sit-to-stand (STS) in older adults

\begin{tabular}{rccc}
\hline Brain area & $\begin{array}{c}\text { Physical STS } \\
\text { number of participants (\%) }\end{array}$ & $\begin{array}{c}\text { Imagined STS } \\
\text { number of participants (\%) }\end{array}$ & $\mathrm{p}$ \\
\hline Frontal lobe & $17(89.5)$ & $16(84.2)$ & 1.000 \\
$14-17 \mathrm{~Hz}$ & $2(10.5)$ & $3(15.8)$ & \\
$10.6-13 \mathrm{~Hz}$ & $0(0)$ & $0(0)$ & \\
$8-10.5 \mathrm{~Hz}$ & & & \\
Temporal lobe & $16(84.2)$ & $13(68.4)$ & \\
$14-17 \mathrm{~Hz}$ & $3(15.8)$ & $2(10.5)$ & \\
$10.6-13 \mathrm{~Hz}$ & $0(0)$ & $4(21.1)$ & \\
$8-10.5 \mathrm{~Hz}$ & $16(84.2)$ & $10(52.6)$ & \\
Parietal lobe & $3(15.8)$ & $5(26.3)$ & \\
$14-17 \mathrm{~Hz}$ & $0(0)$ & $4(21.1)$ & \\
$10.6-13 \mathrm{~Hz}$ & & $10(52.6)$ & \\
$8-10.5 \mathrm{~Hz}$ & $16(84.2)$ & $5(26.3)$ & \\
Occipital lobe & $3(15.8)$ & $4(21.1)$ & \\
$14-17 \mathrm{~Hz}$ & $0(0)$ & & \\
$10.6-13 \mathrm{~Hz}$ & & & \\
$8-10.5 \mathrm{~Hz}$ & &
\end{tabular}

adults ( $p>0.05)$. Self-reported MT during physical STS in young participants was shorter than in older participants ( $<<0.05)$, whereas there was no aging effect on self-reported MT during MI ( $p>0.05$ ) (Table 2).

There was no significant difference in EEG features between physical STS and imagined STS for the frontal and temporal lobes $(\mathrm{p}>0.05)$ in both young and older adults (Tables 3,4$)$. EEG features in young and older participants did only differ for the temporal lobe $(\mathrm{p}<0.05)$ during MI, but not significantly different for frontal lobe $(\mathrm{p}>0.05)$ during physical and imagined STS (Table 5). For the temporal lobe, the EEG during imagined STS in older adults displayed all of three brain waves, including the beta wave (68.4\%), a high frequency of the alpha wave at 10.6-13 Hz (10.5) and a low frequency of the alpha wave at $8-10.5 \mathrm{~Hz}$ (21.1). 
Table 5. Comparison of electroencephalography (EEG) features during physical and imagined sit-to-stand (STS) in young and older adults

\begin{tabular}{|c|c|c|c|c|c|c|}
\hline \multirow[t]{2}{*}{ Brain area } & \multicolumn{2}{|c|}{$\begin{array}{c}\text { Physical STS } \\
\text { number of participants (\%) }\end{array}$} & \multirow[t]{2}{*}{$\mathrm{p}$} & \multicolumn{2}{|c|}{ Imagined STS } & \multirow[t]{2}{*}{$\mathrm{p}$} \\
\hline & Young & Older & & Young & Older & \\
\hline \multicolumn{7}{|l|}{ Frontal lobe } \\
\hline $14-17 \mathrm{~Hz}$ & $20(100)$ & $17(89.5)$ & 0.231 & $20(100)$ & $16(84.2)$ & 0.106 \\
\hline $10.6-13 \mathrm{~Hz}$ & $0(0)$ & $2(10.5)$ & & $0(0)$ & $3(15.8)$ & \\
\hline $8-10.5 \mathrm{~Hz}$ & $0(0)$ & $0(0)$ & & $0(0)$ & $0(0)$ & \\
\hline \multicolumn{7}{|l|}{ Temporal lobe } \\
\hline $14-17 \mathrm{~Hz}$ & $20(100)$ & $16(84.2)$ & 0.106 & $20(100)$ & $13(68.4)$ & $0.008^{*}$ \\
\hline $10.6-13 \mathrm{~Hz}$ & $0(0)$ & $3(15.8)$ & & $0(0)$ & $2(10.5)$ & \\
\hline $8-10.5 \mathrm{~Hz}$ & $0(0)$ & $0(0)$ & & $0(0)$ & $4(21.1)$ & \\
\hline \multicolumn{7}{|l|}{ Parietal lobe } \\
\hline $14-17 \mathrm{~Hz}$ & $20(100)$ & $16(84.2)$ & 0.106 & $1(5)$ & $10(52.6)$ & $<0.00 *$ \\
\hline $10.6-13 \mathrm{~Hz}$ & $0(0)$ & $3(15.8)$ & & $19(95)$ & $5(26.3)$ & \\
\hline $8-10.5 \mathrm{~Hz}$ & $0(0)$ & $0(0)$ & & $0(0)$ & $4(21.1)$ & \\
\hline \multicolumn{7}{|l|}{ Occipital lobe } \\
\hline $14-17 \mathrm{~Hz}$ & $20(100)$ & $16(84.2)$ & 0.106 & $1(5)$ & $10(52.6)$ & $<0.00^{*}$ \\
\hline $10.6-13 \mathrm{~Hz}$ & $0(0)$ & $3(15.8)$ & & $0(0)$ & $5(26.3)$ & \\
\hline $8-10.5 \mathrm{~Hz}$ & $0(0)$ & $0(0)$ & & $19(95)$ & $4(21.1)$ & \\
\hline
\end{tabular}

*Significant difference when comparing EEG features between young adults and older adults.

There were significantly different features of the EEG between physical STS and imagined STS for the parietal lobe $(\mathrm{p}<0.05)$ in young adults. The EEG during physical STS showed the beta wave at $14-17 \mathrm{~Hz}$, whereas the EEG during imagined STS displayed a high frequency of the alpha wave at 10.6-13 Hz (Tables 3, 4) in young adults. On the other hand, almost older adults the EEG during physical STS showed the beta wave at $14-17 \mathrm{~Hz}$, whereas the EEG during imagined STS displayed all of three brain waves, including the beta wave (52.60\%), a high frequency of the alpha wave at $10.6-13 \mathrm{~Hz}$ (26.3) and a low frequency of the alpha wave at 8-10.5 Hz (21.1) (Tables 3,4). EEG features in young and older participants did only differ during MI $(\mathrm{p}<0.05)$ (Table 5).

There were also significantly different features of EEG between physical STS and imagined STS for the occipital lobe $(p<0.05)$ in young adults. The EEG during physical STS showed the beta wave at $14-17 \mathrm{~Hz}$, whereas the EEG during imagined STS displayed a low frequency of the alpha wave at $8-10.5 \mathrm{~Hz}$ (Tables 3, 4) in young adults. On the other hand, almost older adults the EEG during physical STS showed the beta wave at $14-17 \mathrm{~Hz}$, whereas the EEG during imagined STS displayed all of three brain waves, including the beta wave $(52.60 \%)$, the high frequency of the alpha wave at $10.6-13 \mathrm{~Hz}$ (26.3) and the low frequency of the alpha wave at $8-10.5 \mathrm{~Hz}(21.1)$ (Tables 3,4). EEG features in young and older participants did only differ during MI $(\mathrm{p}<0.05)$ (Table 5).

\section{DISCUSSION}

This research aimed to investigate the comparison between the self-reported MT and the EEG feature of physical and imagined STS. The 39 participants were between 20-29 years of age $(n=20)$ and 60-69 years of age $(n=19)$, with normal levels of brain function and imagery ability. The vividness of participants was clear and reasonable.

Unsurprisingly, older participants' self-reported MT during physical STS was longer than young participants. Age-related differences appear to be important during transitional movements because it is widely accepted that aging and a decline in numerous physical performance measures are linked. Some investigators have claimed that strategies of the STS task were slightly different between healthy young and older adults ${ }^{34,35)}$. Much STS research have been carried out on deconditioned older people, because older people often have functional limitations, leading to difficulty in achieving extension of the hips, the legs and the trunk, and they move more slowly ${ }^{36)}$.

Self-reported movement times did not differ between physical and imagined STS movements in young and older adults. Moreover, the ability to generate MI did not differ between young and older participants. The findings go along with Srisupornkornkool's, who compared actual STS and imagined STS with participants in good health. Here, it was found that the period of time for physical STS was similar to that of STS imagery and there was no aging effect on self-reported MT during $\mathrm{MI}^{29)}$. It is generally known that an action has an overt stage and a covert stage. Every overtly executed action implies the existence of a covert stage while a covert action need not have an overt stage. The covert stage is a representation of the action that consists of the purpose of the action, the information needed to practice it, and the possible outcomes. This stage includes not only self-intending action that will become eventually executed action, but also imagined action and recognizing tools ${ }^{37}$. The process of imagining body movements is so similar to the act of performing them that imagined actions are thought to be simulations of their physical counterparts ${ }^{14,38}$. Evidence for this comes from behavioural studies showing that imagined 
actions adhere to the same temporal regularities that are observed in corresponding physical actions, such as temporal scaling of movement duration to distance ${ }^{11,15}$ ), the speed-accuracy tradeoff expressed in Fitts' law ${ }^{39}, 40$ ), adherence to biomechanical constraints $^{41,42)}$, and the same pattern of simulated effort ${ }^{16)}$.

Likewise, neurophysiological evidence supports a unitary mechanism for action representation and execution ${ }^{17,18)}$, and brain imaging also points to common loci of cortical activation between motor imagery and execution ${ }^{19-21,43-48)}$ and similar the excitability of the corticomotor pathway, in term of temporal and spatial characteristics between motor imagery and actual movements ${ }^{49}$. However, according to previous literature reviews, research on the impact of MI on higher-level control for STS movement is still rare.

The results showed that the EEG feature during physical and imagined STS for the frontal and temporal lobes displayed 14-17 Hz of the beta wave in both young and older participants. The EEG feature in young participants for the parietal and occipital lobes during imagined STS differed from during physical standing. In other words, the high frequency of the alpha wave was found at $10.6-13 \mathrm{~Hz}$ and the low frequency of the alpha wave was found at $8-10.5 \mathrm{~Hz}$, respectively. In contrast, the EEG feature for the parietal and occipital lobes during imagined STS in older participants displayed all of three brain waves, especially the beta wave.

The presence of the alpha wave can imply the brain is less stimulated, which leads to relaxation ${ }^{50)}$. In this study, the alpha wave was found in the parietal and occipital lobes during imagery, especially in young people. So, it can be said that the brain had less tasks to perform during imagery, which brought about relaxation, especially considering the occipital lobe displayed the lower frequency rate than the parietal lobe. This evidence supports the study of Guillot and Collet ${ }^{51)}$ who claimed that the stimulation from first person and visual MI is different from that of first person and kinesthetic MI. Whereas kinesthetic imagery necessarily focuses attention on body-internal aspects of motor coordination, visual imagery can focus on bodyexternal, goal-related aspects of the movement. The explanation in previous findings was that both the occipital lobe and the superior parietal lobe will be stimulated if the movement is visualized through imagery. On the other hand, if there is an feeling of movement (kinesthetic imagery), the inferior parietal lobe and the motor-related area, consisting of the premotor and motor areas, will be stimulated. In this study, participants were asked to perform imagined STS by using kinesthetic imagery. Therefore, the parietal and occipital lobes during imagery were less activated in young people.

Interestingly, in older people the beta wave was found more than alpha wave for the parietal and occipital lobes during imagined STS. This result revealed that the parietal and occipital lobes would be stimulated during imagery. Probably, older people are known to accrue deficits in motor planning ${ }^{52)}$ that increase reliance on visual information to guide movements ${ }^{53)}$ as proprioceptive control deteriorates with decreasing muscular strength ${ }^{54)}$. Moreover, there is conflicting evidence for the EEG activity during motor imagery depending on the nature of the task. The beta wave has been shown to reflect the active engagement in encoding and memory retention and highest during focused task-related activation, particularly a newlylearned task ${ }^{55,56)}$. This suggests that young and older participants may respond differently. However, to clarify the impact of aging effects on memory ability, the further study should to screen for working memory (i.e., stroop test or visual recognition memory picture) as inclusion criteria.

The participants in the present study were asked to imagine the feeling of the STS movement, and the result was consistent with previous research in this regard. The results from this study revealed that the temporal and frontal lobes would be stimulated during imagery, similar to the brain functions during actual STS. This is due to the fact that the temporal lobe is part of higher-level sensory processing, which is responsible for stimulus identification and response selection ${ }^{57,58)}$. Even though no external stimulus was shown in the sensory area of the parietal lobe during imagery, during this state, stimuli from working memory was used ${ }^{51,59-62)}$, which takes place in higher-level sensory processing. Both the temporal and parietal lobes would, then, be stimulated. Although there was a high frequency of the alpha wave found in the parietal lobe, implying that there was less stimulus in this area. However, higher frequency of alpha is reflected during states of arousal, attention and readiness to perform cognitive tasks including working memory. These processes play important role for motor imagery because motor imagery is the ability to imagined performance of movement within a complex cognitive organization that requires memory and spatial attention without an overt movement ${ }^{63)}$.

In addition, the results revealed that the frontal lobe was stimulated during imagined STS. This can be attributed to the fact that the frontal lobe is essential for executive movement, processing both stimulus identification and response selection via the prefrontal cortex and association areas, as well as response programming via the supplementary motor cortex ${ }^{57)}$. The response programming directly related to executive movement is mainly the motor program. This program draws the muscles together with the proper force and time needed to respond ${ }^{58)}$.

The current results on brain function during imagined STS supports previous research ${ }^{18,21,40,45,46,62,64)}$, which claims that the brain function process during movement imagery is quite similar to that during the actual movement. Interestingly, this finding found that the ability to generate MI, in term of the period of time, did not differ between young and older people, but the brain activity was dissimilar related to aging. The further study should clarify the impact of motor imagery modalities (e.g. kinesthetic and visual imagery) on the planning and execution of STS movements with respect to age-related differences. Furthermore, the present finding cannot be seen in movement imagery due to the fact that nerve impulses are restrained to the muscle ${ }^{65)}$. Thus, further research should also focus on investigating muscle functions during imagined STS in order to see the nerve impulses for particular muscles. This would shed light for further development of STS-enhancement programs.

In the present research, self-reported MT and the EEG features for the frontal, temporal, parietal and occipital lobes in 
young and older adults were explored under physical and imagined STS movements. The main finding demonstrated that self-reported MT was similar between STS and imagined STS, and the ability to generate MI did not differ between young and older people. Secondly, the brain activity for the frontal and temporal lobes were similar between STS and imagined STS in young and older adults, while the brain activity for the parietal and occipital lobes were different between STS and imagined STS in young adults. Finally, there was age-related difference in the brain area activated during imagined STS. Young adults' imagined movement engaged the frontal and temporal lobes, while older adults' imagined movement occupied all of brain areas to process the motor planning of imagined STS. In conclusion, there was no age-related effect on the ability to generate MI, although the brain areas activated were dissimilar between young and older people for motor planning during MI.

\section{Funding}

This research was supported by Naresuan University.

\section{Conflict of interest}

None.

\section{ACKNOWLEDGEMENTS}

The researchers thank the participants for their time in taking part in this study. Also, the authors acknowledge the Physical Therapy Department, Allied Health Science Faculty, Naresuan University and Buddhachinaraj Hospital, for their support.

\section{REFERENCES}

1) Bohannon RW, Barreca SR, Shove ME, et al.: Documentation of daily sit-to-stands performed by community-dwelling adults. Physiother Theory Pract, 2008, 24: 437-442. [Medline] [CrossRef]

2) Dall PM, Kerr A: Frequency of the sit to stand task: an observational study of free-living adults. Appl Ergon, 2010, 41: 58-61. [Medline] [CrossRef]

3) Roebroeck ME, Doorenbosch CA, Harlaar J, et al.: Biomechanics and muscular activity during sit-to-stand transfer. Clin Biomech (Bristol, Avon), 1994, 9: 235-244. [Medline] [CrossRef]

4) Vander Linden DW, Brunt D, McCulloch MU: Variant and invariant characteristics of the sit-to-stand task in healthy elderly adults. Arch Phys Med Rehabil, 1994, 75: 653-660. [Medline] [CrossRef]

5) Khemlani MM, Carr JH, Crosbie WJ: Muscle synergies and joint linkages in sit-to-stand under two initial foot positions. Clin Biomech (Bristol, Avon), 1999, 14: 236-246. [Medline] [CrossRef]

6) Guralnik JM, Ferrucci L, Simonsick EM, et al.: Lower-extremity function in persons over the age of 70 years as a predictor of subsequent disability. N Engl J Med, 1995, 332: 556-561. [Medline] [CrossRef]

7) Nevitt MC, Cummings SR, Hudes ES: Risk factors for injurious falls: a prospective study. J Gerontol, 1991, 46: M164-M170. [Medline] [CrossRef]

8) Penninx BW, Ferrucci L, Leveille SG, et al.: Lower extremity performance in nondisabled older persons as a predictor of subsequent hospitalization. J Gerontol A Biol Sci Med Sci, 2000, 55: M691-M697. [Medline] [CrossRef]

9) Guralnik JM, Simonsick EM, Ferrucci L, et al.: A short physical performance battery assessing lower extremity function: association with self-reported disability and prediction of mortality and nursing home admission. J Gerontol, 1994, 49: M85-M94. [Medline] [CrossRef]

10) Hughes MA, Myers BS, Schenkman ML: The role of strength in rising from a chair in the functionally impaired elderly. J Biomech, $1996,29: 1509-1513$. [Medline] [CrossRef]

11) Sirigu A, Duhamel JR, Cohen L, et al.: The mental representation of hand movements after parietal cortex damage. Science, 1996, 273: 1564-1568. [Medline] [CrossRef]

12) Seynnes O, Fiatarone Singh MA, Hue O, et al.: Physiological and functional responses to low-moderate versus high-intensity progressive resistance training in frail elders. J Gerontol A Biol Sci Med Sci, 2004, 59: 503-509. [Medline] [CrossRef]

13) Rosie J, Taylor D: Sit-to-stand as home exercise for mobility-limited adults over 80 years of age—GrandStand System may keep you standing? Age Ageing, 2007, 36: 555-562. [Medline] [CrossRef]

14) Jeannerod M: Motor cognition: What actions tell the self. Oxford: Oxford University Press, 2006.

15) Papaxanthis $C$, Schieppati M, Gentili R, et al.: Imagined and actual arm movements have similar durations when performed under different conditions of direction and mass. Exp Brain Res, 2002, 143: 447-452. [Medline] [CrossRef]

16) Cerritelli B, Maruff P, Wilson P, et al.: The effect of an external load on the force and timing components of mentally represented actions. Behav Brain Res, 2000, 108: 91-96. [Medline] [CrossRef]

17) Bonnet M, Decety J, Jeannerod M, et al.: Mental simulation of an action modulates the excitability of spinal reflex pathways in man. Brain Res Cogn Brain Res, 1997, 5: 221-228. [Medline] [CrossRef]

18) Clark S, Tremblay F, Ste-Marie D: Differential modulation of corticospinal excitability during observation, mental imagery and imitation of hand actions. Neuropsychologia, 2004, 42: 105-112. [Medline] [CrossRef]

19) Grèzes J, Decety J: Functional anatomy of execution, mental simulation, observation, and verb generation of actions: a meta-analysis. Hum Brain Mapp, 2001, 12: 1-19. [Medline] [CrossRef] 
20) de Lange FP, Hagoort P, Toni I: Neural topography and content of movement representations. J Cogn Neurosci, 2005, 17: 97-112. [Medline] [CrossRef]

21) Orr EL, Lacourse MG, Cohen MJ, et al.: Cortical activation during executed, imagined, and observed foot movements. Neuroreport, 2008, 19: 625-630. [Medline] [CrossRef]

22) Zijdewind I, Toering ST, Bessem B, et al.: Effects of imagery motor training on torque production of ankle plantar flexor muscles. Muscle Nerve, 2003, 28: 168-173. [Medline] [CrossRef]

23) Sidaway B, Trzaska AR: Can mental practice increase ankle dorsiflexor torque? Phys Ther, 2005, 85: 1053-1060. [Medline]

24) Gentili R, Papaxanthis C, Pozzo T: Improvement and generalization of arm motor performance through motor imagery practice. Neuroscience, 2006, 137: 761-772. [Medline] [CrossRef]

25) Williams JG, Odley JL, Callaghan M: Motor imagery boosts proprioceptive neuromuscular facilitation in the attainment and retention of range-of -motion at the hip joint. J Sports Sci Med, 2004, 3: 160-166. [Medline]

26) Fansler CL, Poff CL, Shepard KF: Effects of mental practice on balance in elderly women. Phys Ther, 1985, 65: 1332-1338. [Medline] [CrossRef]

27) Hamel MF, Lajoie Y: Mental imagery. Effects on static balance and attentional demands of the elderly. Aging Clin Exp Res, 2005, 17: 223-228. [Medline] [CrossRef]

28) Skoura X, Papaxanthis C, Vinter A, et al.: Mentally represented motor actions in normal aging. I. Age effects on the temporal features of overt and covert execution of actions. Behav Brain Res, 2005, 165: 229-239. [Medline] [CrossRef]

29) Srisupornkornkool K: Effect of aging on the planning and execution of sit-to-stand movement. Dissertation, The University of Warwick, Conventry, England, 2014.

30) Saltzman E, Kelso JA: Skilled actions: a task-dynamic approach. Psychol Rev, 1987, 94: 84-106. [Medline] [CrossRef]

31) Wolpert DM, Kawato M: Multiple paired forward and inverse models for motor control. Neural Netw, 1998, 11: 1317-1329. [Medline] [CrossRef]

32) Nussbaum JF, Coupland J: Handbook of communication and aging research. Mahwah: Lawrence Erlbaum Associates Publishers, 2004.

33) Cheng PT, Liaw MY, Wong MK, et al.: The sit-to-stand movement in stroke patients and its correlation with falling. Arch Phys Med Rehabil, 1998, 79: 1043-1046. [Medline] [CrossRef]

34) Ikeda ER, Schenkman ML, Riley PO, et al.: Influence of age on dynamics of rising from a chair. Phys Ther, 1991, 71: 473-481. [Medline] [CrossRef]

35) Pai YC, Naughton BJ, Chang RW, et al.: Control of body centre of mass momentum during sit-to-stand among young and elderly adults. Gait Posture, 1994, 2 : 109-116. [CrossRef]

36) Papa E, Cappozzo A: Sit-to-stand motor strategies investigated in able-bodied young and elderly subjects. J Biomech, 2000, 33: 1113-1122. [Medline] [CrossRef]

37) Jeannerod M: Neural simulation of action: a unifying mechanism for motor cognition. Neuroimage, 2001, 14: S103-S109. [Medline] [CrossRef]

38) Jackson PL, Lafleur MF, Malouin F, et al.: Potential role of mental practice using motor imagery in neurologic rehabilitation. Arch Phys Med Rehabil, 2001, 82: 1133-1141. [Medline] [CrossRef]

39) Decety J, Jeannerod M: Mentally simulated movements in virtual reality: does Fitts's law hold in motor imagery? Behav Brain Res, 1995, 72: 127-134. [Medline] [CrossRef]

40) Stevens JA: Interference effects demonstrate distinct roles for visual and motor imagery during the mental representation of human action. Cognition, 2005, 95: 329-350. [Medline] [CrossRef]

41) Johnson SH: Thinking ahead: the case for motor imagery in prospective judgements of prehension. Cognition, 2000, 74: 33-70. [Medline] [CrossRef]

42) Frak V, Paulignan Y, Jeannerod M: Orientation of the opposition axis in mentally simulated grasping. Exp Brain Res, 2001, 136: 120-127. [Medline] [CrossRef]

43) Ouchi Y, Okada H, Yoshikawa E, et al.: Brain activation during maintenance of standing postures in humans. Brain, 1999, 122: 329-338. [Medline] [CrossRef]

44) Miyai I, Tanabe HC, Sase I, et al.: Cortical mapping of gait in humans: a near-infrared spectroscopic topography study. Neuroimage, 2001, 14: 1186-1192. [Medline] [CrossRef]

45) Malouin F, Richards CL, Jackson PL, et al.: Brain activations during motor imagery of locomotor-related tasks: a PET study. Hum Brain Mapp, 2003, 19: 47-62. [Medline] [CrossRef]

46) Bakker M, De Lange FP, Helmich RC, et al.: Cerebral correlates of motor imagery of normal and precision gait. Neuroimage, 2008, 41: 998-1010. [Medline] [CrossRef]

47) Iseki K, Hanakawa T, Shinozaki J, et al.: Neural mechanisms involved in mental imagery and observation of gait. Neuroimage, 2008, 41: 1021-1031. [Medline] [CrossRef]

48) Jahn K, Deutschländer A, Stephan T, et al.: Brain activation patterns during imagined stance and locomotion in functional magnetic resonance imaging Neuroimage, 2004, 22: 1722-1731. [Medline] [CrossRef]

49) Hashimoto R, Rothwell JC: Dynamic changes in corticospinal excitability during motor imagery. Exp Brain Res, 1999, 125: 75-81. [Medline] [CrossRef]

50) Phrasin A: Analysis and classification of brainwave signals from P300 speller paradigm. Dissertation, King Mongkut's Institute of Technology North Bangkok, Bangkok, Thailand, 2006.

51) Guillot A, Collet C: Contribution from neurophysiological and psychological methods to the study of motor imagery. Brain Res Brain Res Rev, 2005, 50: 387-397. [Medline] [CrossRef]

52) Ketcham CJ, Stelmach GE: Handbook of the psychology of aging, 6th ed. San Diego: Elsevier Academic Press, 2006.

53) Haaland KY, Harrington DL, Grice JW: Effects of aging on planning and implementing arm movements. Psychol Aging, 1993, 8: 617-632. [Medline] [CrossRef]

54) Butler AA, Lord SR, Rogers MW, et al.: Muscle weakness impairs the proprioceptive control of human standing. Brain Res, 2008, 1242: 244-251. [Medline] [CrossRef]

55) Sirigu A, Duhamel JR: Motor and visual imagery as two complementary but neurally dissociable mental processes. J Cogn Neurosci, 2001 , 13: $910-919$. [Medline] [CrossRef]

56) Neuper C, Scherer R, Reiner M, et al.: Imagery of motor actions: differential effects of kinesthetic and visual-motor mode of imagery in single-trial EEG. Brain Res Cogn Brain Res, 2005, 25: 668-677. [Medline] [CrossRef]

57) Shumway-Cook A, Woolacott MH: Motor control: translating research into clinical practice. Philadelphia: Lippincott Williams \& Wilkins, 2007.

58) Schmidt RA, Lee TD: Motor control and learning: a behavioral emphasis. Champaign: Human Kinetics, 2011. 
59) Annett J: Motor imagery: perception or action? Neuropsychologia, 1995, 33: 1395-1417. [Medline] [CrossRef]

60) Jeannerod M: Mental imagery in the motor context. Neuropsychologia, 1995, 33: 1419-1432. [Medline] [CrossRef]

61) Kosslyn SM, Ganis G, Thompson WL: Neural foundations of imagery. Nat Rev Neurosci, 2001, 2: 635-642. [Medline] [CrossRef]

62) Solodkin A, Hlustik P, Chen EE, et al.: Fine modulation in network activation during motor execution and motor imagery. Cereb Cortex, 2004 , 14 : 1246-1255. [Medline] [CrossRef]

63) Angelakis E, Lubar JF, Stathopoulou S, et al.: Peak alpha frequency: an electroencephalographic measure of cognitive preparedness. Clin Neurophysiol, 2004, 115: 887-897. [Medline] [CrossRef]

64) Szameitat AJ, Shen S, Sterr A: Motor imagery of complex everyday movements. an fMRI study. Neuroimage, 2007, 34: 702-713. [Medline] [CrossRef]

65) Hanakawa T, Dimyan MA, Hallett M: Motor planning, imagery, and execution in the distributed motor network: a time-course study with functional MRI. Cereb Cortex, 2008, 18: 2775-2788. [Medline] [CrossRef] 